\title{
ALTERATIONS IN LIVER FUNCTION AS AN INDEX OF TOXEMIA IN PNEUMOCOCCUS LOBAR PNEUMONIA
}

\author{
BY BENEDICT RICHARD HARRIS, M.D.
}

(From the Department of Internal Medicine, Yale University School of Medicine and the Medical Service of the New Haven Hospital, New Haven, Connecticut)

(Received for publication September 7, 1926)

Jaundice, varying from a slight icteric tinting of the sclerae to a pronounced generalized pigmentation of the skin and mucous membranes is not infrequently encountered during the course of lobar pneumonia. Further, if examined for carefully, the presence of urobilin and urobilinogen in the urine is found to be practically constant during the acute febrile period of the disease. Both jaundice and urobilinuria may be considered as probable indicators of liver damage, yet despite the fact their occurrence has long been appreciated, with the exception of the icterus index studies of Bernheim (1), the work of Kahler (2), and a few isolated case reports in the recent literature, there has been no detailed study of liver function in pneumonia. Bernheim, in a study of the icterus index in various conditions, found it to be greater than normal in most of the cases of pneumonia studied. Kahler, working with phenoltetrachlorphthalein, commented on the frequency with which high degrees of retention were observed in pneumonia. The lack of a detailed study of the liver function in pneumonia may probably be attributed in part to the lack of trustworthy methods for the clinical determination of liver function. The comparatively recent introduction of the dye elimination tests and of the improved methods for the quantitative determination of circulating bile pigments has made it possible to carry on such a study. Accordingly an investigation was undertaken in a series of cases of pneumococcus lobar pneumonia to determine (1) if pneumonia is uniformly attended with alterations in liver function; (2) if the various types of infecting pneumococci produce characteristic degrees of hepatic dysfunction, and (3) if there is any parallelism between the 
degree of toxemia, as estimated by the clinical signs and ultimate outcome, and the amount of functional disturbance of the liver.

The mechanism of liver damage in pneumonia is not clearly understood. Among the recognized functions of the liver are the removal and rendering innocuous of circulating toxins and the temporary or permanent immobilization of circulating organisms. Such toxins and organisms are presumably present in pneumonia. As an additional factor in the causation of liver damage in pneumonia, Resnik and Keefer (3) have suggested the presence of anoxic anoxemia. It is conceivable tht the liver may be damaged to an extent sufficient to be detected and measured by the improved functional tests now available.

Various types of structural change in the liver have been described. In the experimental pneumonias in monkeys, F. G. Blake and R. L. Cecil (4) found, as a rule, only cloudy swelling of the liver parenchyma. This, too, is the usual type of change found in patients who have succumbed to the disease. Acute catarrhal cholangeitis, actual inflammatory hepatitis, perihepatitis, cirrhosis, and fatty -change have also been described as occurring during the course of acute lobar pneumonia. Norris (5) cites the collected statistics of the hepatic complications of pneumonia as follows: "Of 22,544 cases 373 or 1.65 per cent had jaundice, and of 344 so affected, 15.7 per cent died; of 173 patients, 20.23 per cent had a palpable liver, in seven of whom the liver was tender; of 201 patients, one had perihepatitis and one had liver abscess; of 3644,19 (0.52 per cent) showed cirrhosis of the liver. Of 144 autopsies, 5.55 per cent showed nutmeg liver; of 517 autopsies, 5.9 per cent showed fatty liver; of 239 autopsies, 5.29 per cent had acute parenchymatous hepatitis; of 400 autopsies 2 had jaundice; of 127 autopsies, 1.5 per cent had cholecystitis.

\section{PLAN OF STUDY}

Liver function tests were performed on all definite cases of pneumococcus lobar pneumonia which were admitted to the Infectious Disease Pavilion of the New Haven Hospital. Patients below the age of thirteen, obviously senile patients, those with atypical signs, and those giving a history of chronic alcoholism were not included. The estimation of the rate of disappearance of the intravenously-injected dye, phenoltetrachlorphthalein, according to the method of S. M. 
Rosenthal (6), was first employed as a measure of liver function. In the latter part of the study the dye bromsulphalein was used. Functional tests were performed on all patients during the acute febrile period of the disease and, in many instances, again after convalescence had been established. The amount of serum bilirubin was estimated according to the quantitative method of van den Bergh (7), and the presence of urobilinogen and urobilin in the urine spectroscopically and according to the method of Schlessinger (8).

Liver function tests were also carried out on a heterogeneous group of cases of infectious diseases as a control for the estimation of the effect on liver function of fever, infection, and toxemia when these were not due to the pneumococcus. Similarly a small group of cases of pulmonary tuberculosis were studied to serve as a control for the effect on liver function of pulmonary damage due to causes other than the pneumococcus.

\section{DESCRIPTION OF METHODS}

Phenoltetrachlorphthalein test. With a few minor variations, the technic described by Rosenthal was followed for the performance of the phenoltetrachlorphthalein test. The test used is as follows: 5 milligrams of the dye for each kilogram of body weight is given intravenously with from 40 to $50 \mathrm{cc}$. of physiologic sodium chloride. The solution is first prepared by making a dilution of phenoltetrachlorphthalein in saline so that each cubic centimeter of the solution is equivalent to either 6 or $8 \mathrm{mgm}$. of the dye, depending on the weight of the patient. The necessary amount of this solution is then injected into one of the large veins of the arm by means of a carefully graduated $50 \mathrm{cc}$. syringe. A 4- or 5 -cc. sample of blood is taken one hour after the injection. The blood is withdrawn with a different syringe from the vein of the opposite arm to obviate the possibility of contamination with any of the dye that might have adhered to the vein wall or to the syringe employed. After the blood has coagulated the serum is separated from the cells by centrifugation and transferred to two $10 \mathrm{~mm}$. test tubes. To one of these tubes, which should contain approximately $0.8 \mathrm{cc}$. of serum, $0.2 \mathrm{cc}$. of a 5 per cent sodium hydroxide solution is added in order to produce an alkaline medium in which the purple color of the dye develops. The concentration of the dye in the alkalinized serum is then determined by comparison with freshly prepared standards in a simple comparator and by direct sunlight. In order to compensate for the color of the serum, the tube containing unalkalinized serum is placed behind the standard on one side of the comparator and on the other side a tube containing distilled water is placed in front of the tube of alkalinized serum. The figure obtained by the comparison represents the concentration of the dye retained in the blood serum at the time of withdrawal of blood. 


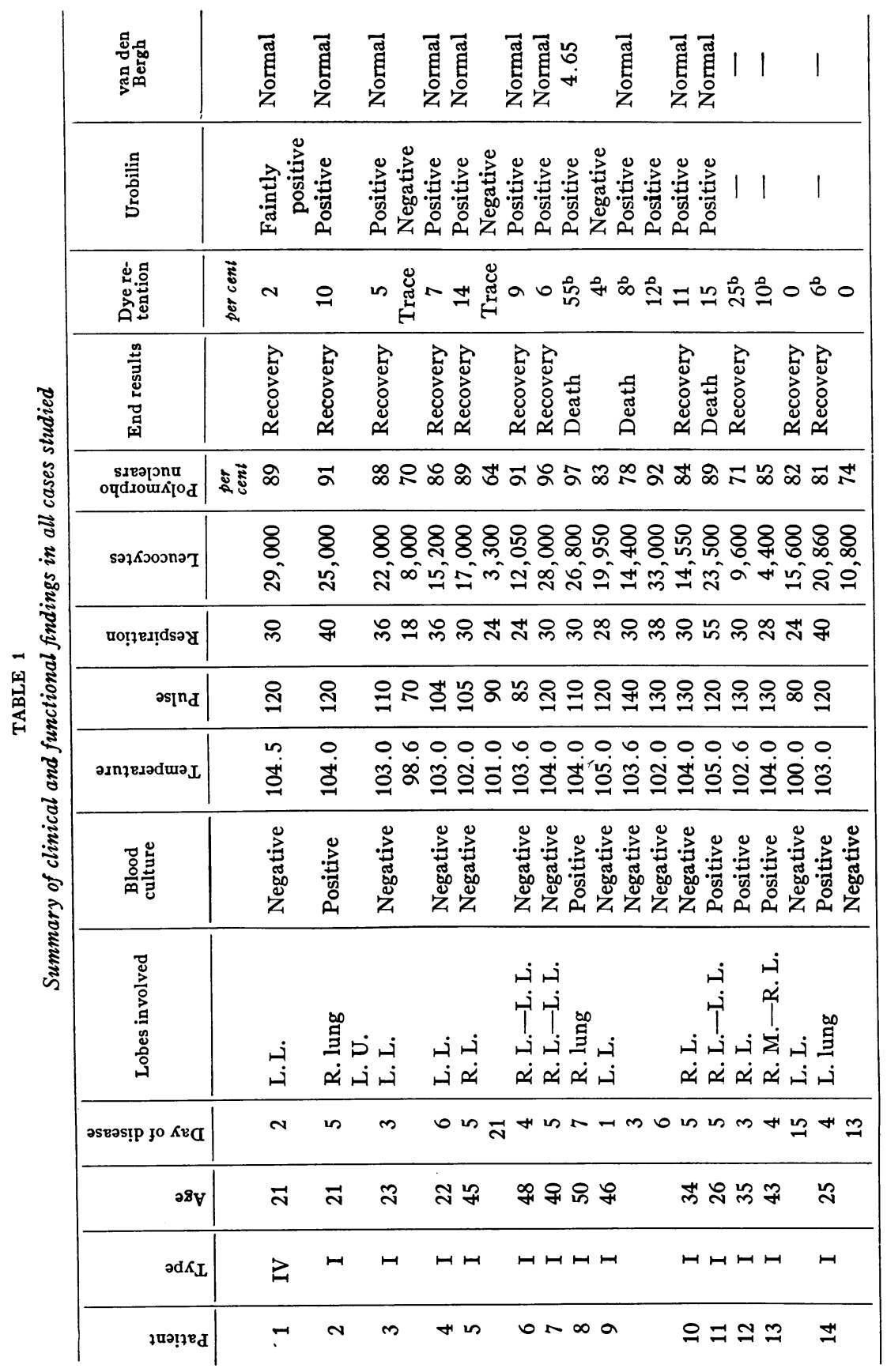




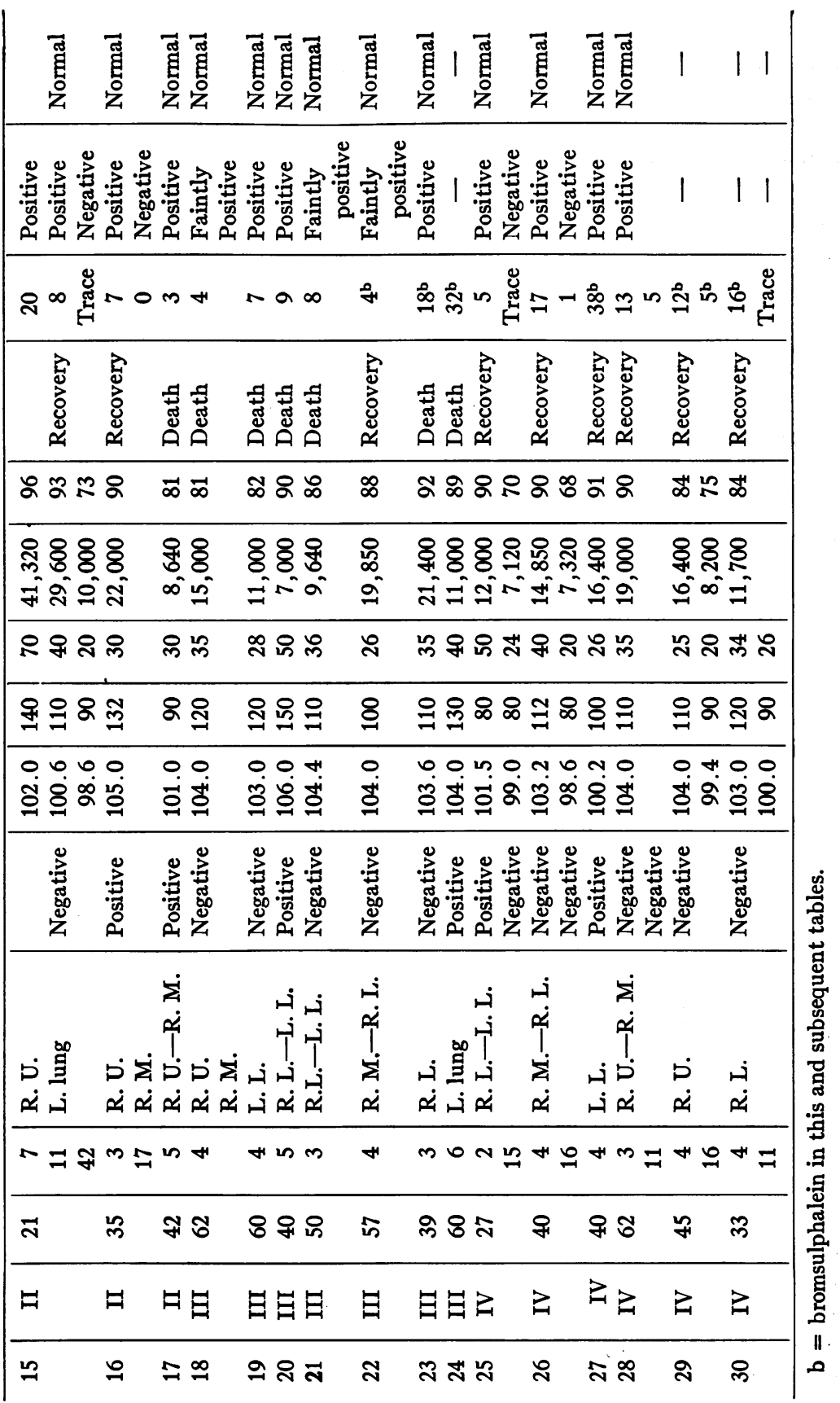


The standards are prepared as follows: $10 \mathrm{mgm}$. of phenoltetrachlorphthalein is added to $100 \mathrm{cc}$. of distilled water. This strength was suggested by Rosenthal as representing the approximate concentration that would be reached if all the injected dye remained in the plasma. This solution is considered as representing a standard of 100 per cent and from this solution a series of standards is prepared in small uniform-sized 10-mm. tubes ranging from 2 to 40 per cent. To each tube one or two drops of 5 per cent sodium hydroxide solution is added in order to bring out the color.

Bromsulphalein ${ }^{1}$ test. The technic first employed was similar to that described for the use of phenoltetrachlorphthalein with these exceptions: 2 mgm. of the dye per kilogram of body weight is the dosage employed; the drug is injected in 5 per cent solution, undiluted; the sample of blood is withdrawn 30 minutes after injection; and the 100 per cent standard is prepared by adding $4 \mathrm{mgm}$. of bromsulphalein to $100 \mathrm{cc}$. of water alkalinized with $0.25 \mathrm{cc}$. of 10 per cent sodium hydroxide. This technic was subsequently modified as follows: The dosage was increased to $5 \mathrm{mgm}$. per kilogram of body weight; the sample of blood was withdrawn $45 \mathrm{~min}$ utes after injection; and the 100 per cent standard was prepared by adding $10 \cdot \mathrm{mgm}$. of bromsulphalein to $100 \mathrm{cc}$. of water alkalinized with $0.25 \mathrm{cc}$. of 10 per cent sodium hydroxide.

Serum bilirubin. The technic described by van den Bergh was followed in detail: $0.5 \mathrm{cc}$. of serum is precipitated with $1 \mathrm{cc}$. of 95 per cent alcohol and centrifuged. To $1 \mathrm{cc}$. of the clear supernatant fluid is added $0.5 \mathrm{cc}$. of 95 per cent alcohol and $0.25 \mathrm{cc}$. of a freshly-prepared solution of Ehrlich's diazo reagent. The color obtained is compared in a Duboscque colorimeter with a standard solution, and after accounting for dilution, the result is expressed in "units." Normal human blood serum contains 0.2 to 0.5 unit of bilirubin (i.e., from 1 in 1,000,000 to 1 in 400,000).

Urobilin and urobilinogen. No attempt was made to determine these substances separately.

Spectroscopic method. After first acidifying the urine with a small quantity of hydrochloric acid to make the spectrum more distinct, the urine is examined in the spectroscope. Acid urobilin solutions, when very concentrated or in thick layers, absorb the entire blue end of the spectrum as far as the middle of the green. On the other hand, a thin layer or a less concentrated solution shows an absorption between the green and the blue. In contrast to urobilin the biliary pigments absorb the spectrum diffusely.

${ }_{1}^{1}$ The modified technic is based on a clinical study of the application of bromsulphalein as a test substance for liver function in which it was found that the employment of the larger dose of the dye facilitates the reading of the amount of dye retention when this is small and introduces no error if the sample of blood is withdrawn $\mathbf{4 5}$ minutes after the injection of the dye. In a group of normal individuals, the blood serum was uniformly free of dye 45 minutes after injection in the dosage of $5 \mathrm{mgm}$. per kilogram of body weight. 
Schlessingers test. The urine is rendered strongly alkaline with ammonia, filtered, and a few drops of a 10 per cent alcoholic solution of zinc chloride are added. A beautiful green florescence occurs if urobilin is present.

\section{RESULTS OF STUDY}

1. Are alterations in liver function uniformly present during the course of acute lobar pneumonia? In this series, dye retention not to exceed 2 per cent in one hour is considered normal. An analysis of

TABLE 2

Liver function tests in pneumococcus pneumonia Types $I$ and $I I$

\begin{tabular}{|c|c|c|c|c|c|c|}
\hline \multirow{3}{*}{ Patient } & \multirow{3}{*}{ Age } & \multirow{3}{*}{ Outcome } & & of dise & & \multirow{3}{*}{ Type } \\
\hline & & & $1-2$ & $3-4$ & $5-7$ & \\
\hline & & & \multicolumn{3}{|c|}{ Per cent of dye retention } & \\
\hline 9 & 46 & Died 6th day & $4^{b}$ & $8^{b}$ & $12^{b}$ & $I^{*}$ \\
\hline 3 & 23 & Recovered & & 5 & & I \\
\hline 14 & 25 & Recovered & & $6^{b}$ & & $I^{*}$ \\
\hline 6 & 48 & Recovered & & 9 & & $\mathbf{I}$ \\
\hline 13 & 43 & Recovered & & $10^{b}$ & & $I^{*}$ \\
\hline 12 & 35 & Recovered & & $25^{b}$ & & $I^{*}$ \\
\hline 7 & 40 & Recovered & & & 6 & $\mathbf{I}$ \\
\hline 2 & 21 & Recovered & & & 10 & $I^{*}$ \\
\hline 10 & 34 & Recovered & & & 11 & $\mathbf{I}$ \\
\hline 5 & 45 & Recovered & & & 14 & $\mathbf{I}$ \\
\hline 11 & 26 & Died & & & $15^{b}$ & $I^{*}$ \\
\hline 4 & 22 & Recovered & & & 6 & I \\
\hline 8 & 50 & Died & & & $55^{b}$ & $I^{*}$ \\
\hline 16 & 35 & Recovered & & 7 & & II $^{*}$ \\
\hline 17 & 42 & Died & & 3 & & $\mathrm{II}^{*}$ \\
\hline 15 & 21 & Recovered & & & 20 & II \\
\hline
\end{tabular}

* Positive blood culture.

table 1 shows that only one patient (patient no. 1) may be considered to have a normal functional test. All of the remaining have a retention of the dye from 3 to 20 per cent in the cases where phenoltetrachlorphthalein was employed, and from 2 to 55 per cent with bromsulphalein. The higher readings with bromsulphalein are to be expected, since comparative studies in known liver disease have shown that the retention of bromsulphalein in the blood serum 30 minutes after in- 
jection is approximately twice that of phenoltetrachlorphthalein one hour after injection. All cases, at some stage during the acute febrile period of the disease showed urobilin in the urine. The serum bilirubin fell within normal limits in all cases except no. 8 who had 4.65 units. This patient had manifest generalized icterus, and showed 55 per cent retention of bromsulphalein. In none of the others did there seem to be any relationship between the degree of dye retention

TABLE 3

Liver function tests in pneumococcus pneumonia Types III and IV

\begin{tabular}{|c|c|c|c|c|c|c|}
\hline \multirow{3}{*}{ Patient } & \multirow{3}{*}{ Age } & \multirow{3}{*}{ Outcome } & \multicolumn{3}{|c|}{ Day of disease } & \multirow{3}{*}{ Type } \\
\hline & & & $1-2$ & 3-4 & $5-7$ & \\
\hline & & & \multicolumn{3}{|c|}{ Per cent of dye retention } & \\
\hline 21 & 50 & Died & & 8 & & III \\
\hline 23 & 39 & Died & & $18^{b}$ & & III \\
\hline 22 & 57 & Recovery & & $4^{b}$ & & III \\
\hline 18 & 62 & Died & & 4 & & III \\
\hline 19 & 60 & Died & & 7 & & III \\
\hline 20 & 40 & Died & & & 9 & III* \\
\hline 24 & 60 & Died & & & $18^{b}$ & III* \\
\hline 1 & 21 & Recovery & 2 & & & IV \\
\hline 25 & 27 & Recovery & 5 & & & IV $^{*}$ \\
\hline 28 & 62 & Recovery & & 13 & & IV \\
\hline 29 & 45 & Recovery & & $12^{b}$ & & IV \\
\hline 30 & 33 & Recovery & & $16^{b}$ & & IV \\
\hline 26 & 40 & Recovery & & 17 & & IV \\
\hline 27 & 40 & Recovery & & $38^{\mathrm{b}}$ & & IV $^{*}$ \\
\hline
\end{tabular}

* Positive blood culture.

and the amount of bilirubin in the serum. Patient no. 1 who showed a retention of only 2 per cent of the dye was a very early case and might have shown evidence of dysfunction had another test been performed during the latter part of the acute febrile period. When a second liver test was performed during convalescence, abnormal dye retention was never encountered, an indication of restoration of normal liver function.

2. Do the various types of infecting pneumococci produce characteristic degrees of hepatic dysfunction? On analysis of tables 2 and 3, 
in which the cases are arranged according to the type of infecting pneumococci and according to the day of the disease, in order to make conditions at least roughly comparable, no striking or characteristic differences among the various types can be detected with possible exception of Type IV pneumonia. In all of the latter there is a greater degree of dye retention than in the other three groups during the third and fourth days of the disease.

3. Is there any parallelism between the degree of functional disturbance of the liver and the degree of toxemia, as estimated by the clinical signs and the ultimate outcome? It will be seen from tables 2 and 3 that in pneumonias of Types I and III with one exception (table 2, patient 9) the greatest degree of retention was found in fatal cases. In the Type II group no such relationship between retention and mortality appeared. When judged from the standpoint of toxemia as manifested by clinical signs, and not considering the ultimate outcome, the degree of retention seemed to parallel the severity of the disease. The striking feature is that there was no evidence of greater disturbance in the Type III pneumonias with a high mortality rate than in the other types of pneumonia where the mortality rate was conspicuously lower. It is evident also, from an analysis of the tables that the degree of dye retention tends to increase as the disease progresses, during the acute febrile period, the greater degrees of retention in each group occurring during the latter part of the first week.

Control study. Analysis of the results obtained in the heterogeneous group of infectious diseases indicates that typhoid fever, scarlet fever, and erysipelas may be accompanied by mild disturbances of liver function, minimal however, in comparison with that usually seen in the group of pneumococcus pneumonias. Acute tonsillitis, though accompanied by high fever, showed no dye retention. Although several of the patients in the tuberculosis group had extensive involvement of the lungs, impairment of the liver function was uniformly minimal or absent. Only in the cases of tuberculous pleurisy with effusion was the amount of liver dysfunction comparable to that found in most of the cases of pneumonia. In all instances the tests were performed during the febrile period of the disease. 
LIVER FUNCTION AS INDEX OF TOXEMIA

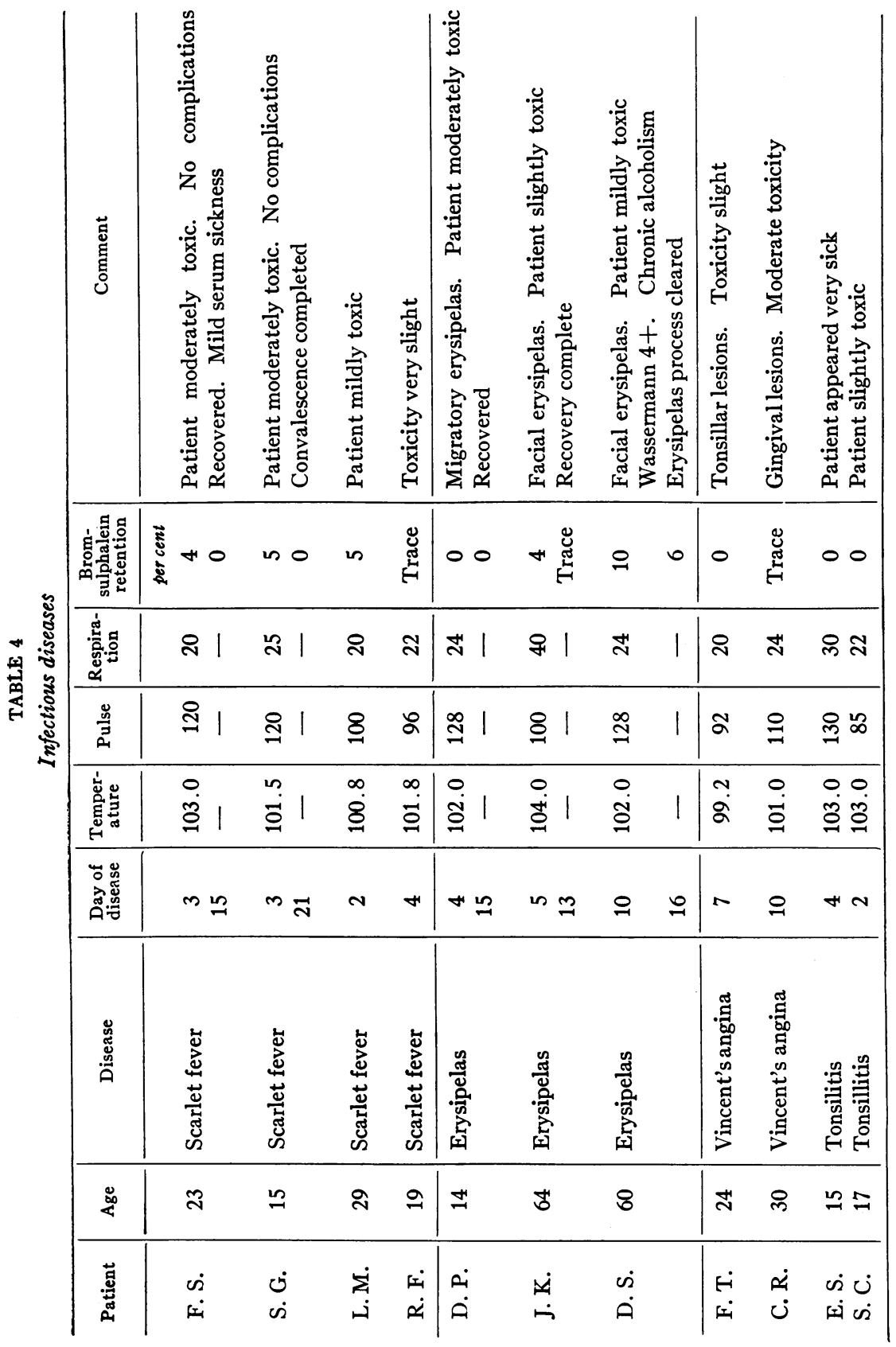




\begin{tabular}{|c|c|c|c|c|c|c|c|}
\hline 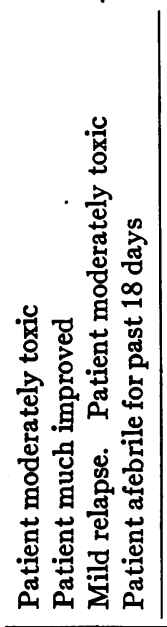 & 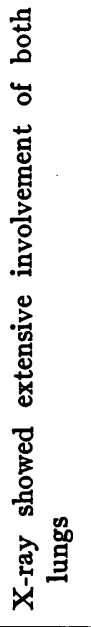 & 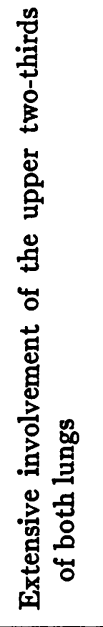 & 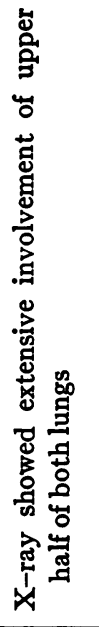 & 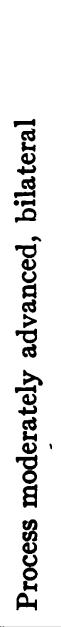 & 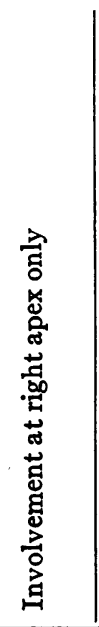 & 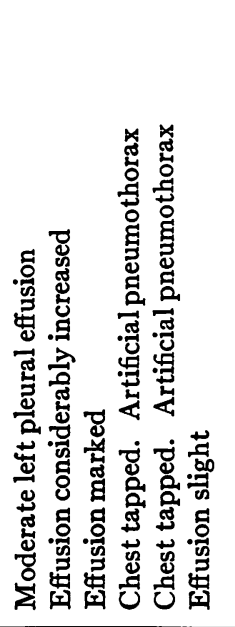 & 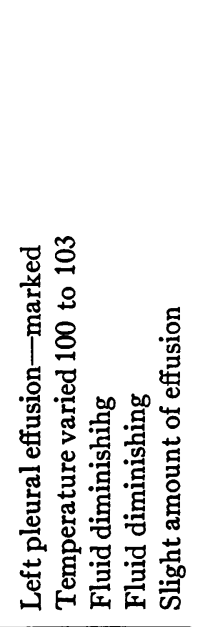 \\
\hline 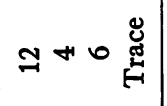 & $H$ & + & in & + & 0 & $0 \simeq \simeq \mid$ in & I I $a$ in \\
\hline$\infty \mathbb{N} \mid \mathbb{N}$ & జి & $\nexists$ & 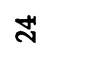 & $\mathbb{N}$ & ה & EI $|1| 1 \mid$ & $21|1|$ \\
\hline ஃむ゙ & I & 8 & 苛 & 2 & \& & $\infty \begin{array}{lllll}\infty & 1 & 1 & 1 & 1\end{array}$ & 81111 \\
\hline$\left|\begin{array}{cccc|}\infty & 0 & 0 & 0 \\
0 & 0 & 0 & 0 \\
0 & 0 & 0 & 0\end{array}\right|$ & בั & $\stackrel{+}{3}$ & : & 茴 & $\begin{array}{l}0 \\
\infty\end{array}$ & $\stackrel{0}{\dot{a}} 11111$ & 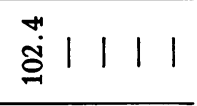 \\
\hline 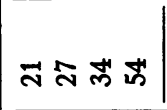 & 1 & I & 1 & 1 & 1 & 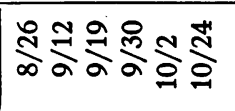 & 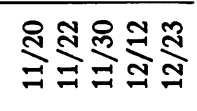 \\
\hline 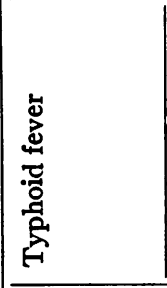 & 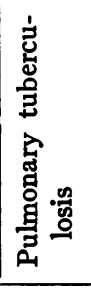 & 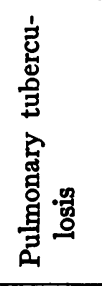 & 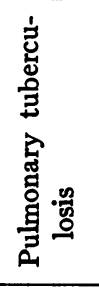 & 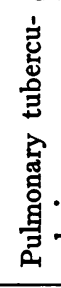 & 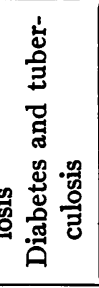 & 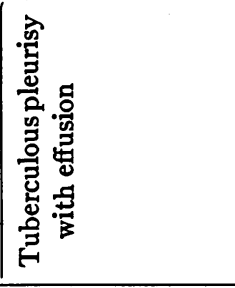 & 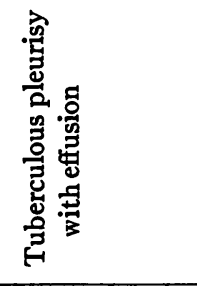 \\
\hline F & 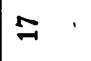 & 苟 & $\hat{m}$ & $\bar{N}$ & $m$ & $\approx$ & 8 \\
\hline $\begin{array}{l}\text { मि } \\
\text { 田 }\end{array}$ & $\dot{\vec{j}}$ & $\stackrel{\dot{i}}{\dot{m}}$ & $\stackrel{\dot{a}}{\sim}$ & 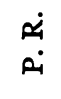 & $\dot{ن}$ & 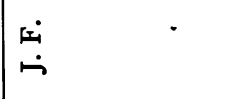 & 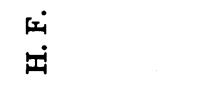 \\
\hline
\end{tabular}




\section{COMMENT}

Although jaundice occurs relatively infrequently, the practically constant urobilinuria and the presence of dye retention indicate that the liver is uniformly affected during the acute febrile period of lobar pneumonia. The results obtained in this investigation serve to strengthen the importance of the conception that pneumonia is not only a local disease attended by mechanical and chemical changes in the cardio-respiratory mechanism, but one attended by general toxemia whch may affect the various systems of the body. Degrees of liver dysfunction may be found which are comparable to those encountered in diseases such as cirrhosis of the liver and metastatic carcinoma of the liver.

The degree of retention of the dye, in itself, affords no index of the toxemia and ultimate outcome. It must be considered in conjunction with the type of infecting pneumococcus and the day of the disease on which the test was performed. In general, a high retention early in the disease in Types I and III pneumonias may be considered as indicating severe toxemia, whereas its significance is considerably less in pneumonia caused by the Type IV pneumococcus. There seems to be no relationship between the degree of dye retention and ultimate outcome in Type II pneumonia. One cannot infer that the different functional results found in the various types of pneumonia are due to distinctive characteristics of the organisms themselves or to the toxins elaborated by them. They may rather be due to differences in the individuals. The most significant conclusion to be derived from the investigation is that retention of the dye is uniformly encountered during the acute febrile period of the disease.

The results obtained in the control group of infectious diseases indicate that the function of the liver is more impaired in pneumonia than in some of the other types of infectious diseases. Fever alone is not responsible for the liver damage as comparable elevations of temperature were present in some of the other disease groups without equivalent disturbances of liver function. The presence of only minimal functional disturbances during the toxic period of scarlet fever suggests that if the disturbances of function encountered in pneumonia are due to circulating toxins, these toxins have a more 
specific affinity for the liver. Structural damage of the lung tissue, in itself, is not the important factor in the production of liver dysfunction, as evidenced by the normal findings even in the presence of advanced pulmonary tuberculosis. The higher retentions in the presence of tuberculous pleural effusions are difficult to interpret. In both cases studied, removal of the effusion fluid was followed by moderate improvement of liver function.

The factor of anoxic anoxemia could not be adequately studied in this investigation and further work along this line will be carried out. The cases where anoxic anoxemia is marked, e.g. streptococcus pneumonia and essential emphysema were not available during the period of this investigation.

\section{SUMMARY}

In order to determine the effect of pneumococcus lobar pneumonia on hepatic function, dye elimination tests, serum bilirubin determinations, and urine urobilinogen and urobilin tests were performed on thirty patients, of which 13 were due to pneumococcus Type I, 3 to pneumococcus Type II, 7 to pneumococcus Type III, and 7 to pneumococcus Type IV. Dye retention was found to occur consistently, the degree increasing as the disease progressed. In considering the disease as a whole, no definite relationship between the severity of the infection (as measured by outcome) and the degree of liver dysfunction was found. When considered according to the type of infecting pneumococcus, a suggestive relationship was found in the pneumonias of Types I and III. Following recovery, dye retention was not present, indicating no permanent liver injury. Urobilinuria was consistently present during the acute febrile period of the disease. The serum bilirubin was within normal limits in all cases except one, a patient with manifest jaundice. Impairment of function in the Type III pneumonias with a mortality of 87 per cent was not greater than in the Types I, II, and IV, with approximately 18 per cent mortality.

An investigation of the liver function in a heterogeneous group of infectious diseases revealed either minimal alterations of liver function as contrasted with the group of pneumonias or none at all. This is taken to indicate that fever or infection, in themselves are not suffcient to alter liver function markedly, rather that the changes found 
in the pneumococcus pneumonias are probably due to an accompanying toxemia which has a specific affinity for the liver. No significant alterations of liver function were found in cases of advanced pulmonary tuberculosis, indicating that structural damage of the lungs is not alone responsible for the changes found in the group of pneumonias.

\section{BIBLIOGRAPHY}

(1) Bernheim, A. R., Jour. Amer. Med. Assoc., 1924, lxxxii, 291. Icterus Index (A Quantitative Estimation of Bilirubinemia); Aid in Diagnosis and Prognosis.

(2) Kahler, H., Klin. Wchnschr., 1925, iv, 2421. Zur Leberfunktionsprufung Mittels Farbstoffen.

(3) Keefer, C. S. and Resnik, W. H., Jour. Clin. Invest., 1926, ii, $375 . \quad$ Jaundice Following Pulmonary Infarction in Patients with Myocardial Insufficiency; I. A Clinical Study.

(4) Blake, F. G., and Cecil, R. L., Jour. Exp. Med., 1920, xxxi, 445. Studies on Experimental Pneumonia. II. Pathology and Pathogenesis of Pneumococcus Lobar Pneumonia in Monkeys.

(5) Norris, G. W., Modern Medicine, Osler and McCrae, 2nd edition, 1913, Philadelphia.

(6) Rosenthal, S. M., Jour. Amer. Med. Assoc., 1922, lxxix, 2151. A New Method of Testing Liver Function with Phenoltetrachlorphthalein.

(7) Van den Bergh, Hijmans, Quoted by McNee, J. W.: Quart. Jour. Med., 1923, xvi, 390. Jaundice: A Review of Recent Work.

(8) Potter, N. B., Sahli's Diagnostic Methods, 2nd Edition, 1911, Philadelphia. p. 584. 